\title{
Peningkatan Kemampuan Desain Grafis untuk Meningkatkan Kreativitas Dakwah pada PC IPM Medan Area
}

\author{
Improved Graphic Design Ability to Improve Creativity Da'wah on PC IPM Medan Area
}

Faizal Hamzah Lubis*
Fadhil Pahlevi Hidayat
Sigit Hardiyanto
Department of Communication
Sciences, Universitas
Muhammadiyah Sumatera Utara,
Medan, North Sumatera, Indonesia
email: faizalhamzah@umsu.ac.id
Kata Kunci
Dakwah
Desain Grafis
Medan
Keywords:
Da'wah
Graphic Design
Medan
Accepted: September 2021
Published: January 2022

\begin{abstract}
Abstrak
Hidup di era digital membuat desain grafis menjadi salah satu keterampilan yang harus dimiliki oleh masyarakat khususnya remaja. Desain grafis dapat menjadi kebutuhan dalam berbagai bidang, salah satunya dalam bidang dakwah. Desain grafis adalah sebagai bentuk seni yang memiliki tujuan sebagai bentuk solusi dalam menyelesaikan masalahmasalah komunikasi dengan memanfaatkan elemen-elemen grafis, seperti warna, garis, bentuk, dan lain-lainnya. Sebagai seorang desain ada beberapa hal yang perlu disiapkan seperti wawasan, keterampilan, kepekaan, dan kreativitas. Bidang kompetensi desain grafis yang harus dikuasai, yaitu sikap (attitude), pengetahuan, keterampilan, dan kepekaan (skill, knowledge, and sensibility), serta bakat dan kreativitas (creativity) sehingga dapat menghasilkan berbagai bentuk karya yang menarik. Kemudian, seseorang yang memiliki kemampuan desain haruslah cerdas dalam berstrategi dan taktis dengan memiliki keahlian atau kemampuan untuk desain grafis tidak hanya dapat meningkatkan kemampuan kreativitas atau seni saja bagi seseorang akan tetapi juga dapat menjadi salah satu untuk cara untuk meningkatkan kreativitas seseorang dalam mendesain pesan atau isi yang digunakan sebagai berdakwah yang dapat menyiarkan ajaran Islam dan nilai-nilai Kemuhammadiyahan dalam era digital saat ini. Melalui kegiatan ini PC IPM Medan Area mendapatkan pengetahuan, pemahaman, serta kemampuan dalam menciptakan desaindesain grafis.
\end{abstract}

\begin{abstract}
Living in the digital age makes graphic design one of the skills that people, especially teenagers, must have. Graphic design can be a necessity in various fields, one of which is in the area of da'wah. Graphic design is an art form that has a goal as a form of a solution in solving communication problems by utilizing graphic elements, such as colors, lines, shapes, and others. As a designer, several things need to be prepared, such as insight, skills, sensitivity, and creativity. The areas of graphic design competence that must be mastered are attitudes, knowledge, skills, sensitivity, talent, and creativity to produce various exciting forms of work. Then, someone who has design skills must be strategic and tactical by; having the skills or abilities for graphic design not only can increase creativity or the artistic ability for someone but can also be a way to increase one's creativity in designing messages or content, which is used as da'wah which can broadcast Islamic teachings and Muhammadiyah values in today's digital era. Through this activity, PC IPM Medan Area will gain knowledge, understanding, and create graphic designs.
\end{abstract}

(C) 2022 Faizal Hamzah Lubis, Fadhil Pahlevi Hidayat, Sigit Hardiyanto. Published by Institute for Research and Community Services Universitas Muhammadiyah Palangkaraya. This is Open Access article under the CC-BY-

SA License (http://creativecommons.org/licenses/by-sa/4.0/). DOI: https://doi.org/10.33084/ pengabdianmu.v7i1.2308

\section{PENDAHULUAN}

Hidup di era digital membuat desain grafis menjadi salah satu keterampilan yang harus dimiliki oleh masyarakat khususnya remaja. Desain grafis dapat menjadi kebutuhan dalam berbagai bidang, salah satunya dalam bidang dakwah dengan menggunakan dunia digital. Pesan-pesan dakwah melalui digital dengan menggunakan desain grafis yang menarik maka akan lebih menambah ketertarikan pembaca untuk mengetahui lebih lanjut tentang apa yang disampaikan. 
Istilah desain grafis dikenal dalam bahasa Yunani, yakni Graphein yang artinya menggambar atau menulis. Pemaknaan seni grafis tersebut dimaknai sebagai seni dalam menggambar dua dimensi yang mencakup beberapa bentuk karya yang dicetak atau karya seni yang diperbanyak, seperti: fotografi, lukisan, menggambar, dan lain sebagainya (Kusrianto, 2009; Walisyah, 2019).

Desain grafis adalah sebagai bentuk seni yang memiliki tujuan sebagai bentuk solusi dalam menyelesaikan masalahmasalah komunikasi dengan memanfaatkan elemen-elemen grafis, seperti warna, garis, bentuk, dan lain-lainnya. Hasil visual desain grafis nantinya diharapkan dapat menjadi sarana untuk menyampaikan informasi atau pesan secara efektif hingga dapat membentuk sebuah makna akan sesuatu hal (Yahya et al., 2020). Manfaat desain grafis dalam kehidupan sehari-hari terasa begitu nyata, misalnya digunakan untuk presentasi tugas atau materi dalam perkuliahan yang dapat kita desain sesuai dengan apa yang kita inginkan sehingga orang yang melihatnya tidak membosankan. Pada dunia bisnis, desain grafis sangat membantu seperti dalam pembuatan logo, brosur, kartu nama, spanduk, dan lain-lain (Pratiwi \& Danugiri, 2020; Yahya et al., 2020). Menurut Widya dan Darmawan (2016), terdapat berbagai hal yang berkaitan dengan desain grafis, yakni: percetakan, internet, komputer, jasa konsultan desain, penerbitan, media cetak elektronik, industri dan manufaktur, fotografi dan ilustrasi, jasa komunikasi pemasaran, serta produsen dan pemasok media cetak. Berikut kaitan desain grafis tersebut yang ditunjukkan pada Gambar 1:

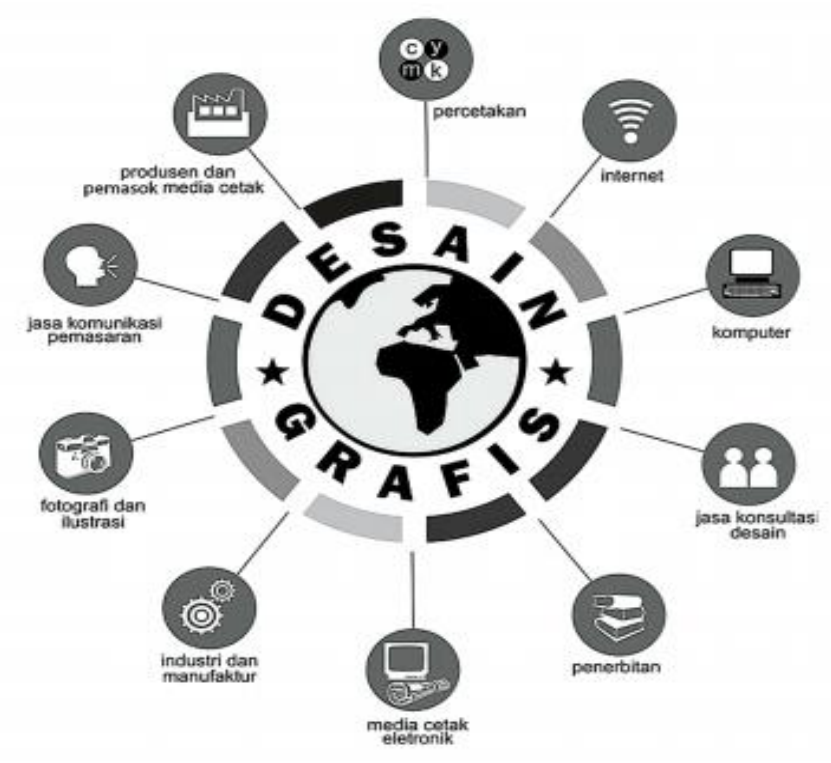

Gambar 1. Hal-Hal yang berkaitan dengan desain grafis

Sebagai seorang desain ada beberapa hal yang perlu disiapkan seperti wawasan, keterampilan, kepekaan, dan kreativitas. Kemudian, seseorang yang memiliki kemampuan desain haruslah cerdas dalam berstrategi dan taktis. Bidang kompetensi desain grafis yang harus dikuasai, yaitu sikap (attitude), pengetahuan, keterampilan, dan kepekaan (skill, knowledge, and sensibility), serta bakat dan kreativitas (creativity) sehingga dapat menghasilkan berbagai bentuk karya yang menarik (Murdiati et al., 2020; Lisnawita et al., 2020).

Dari berbagai hal diatas, dapat dikatakan bahwa kemampuan desain grafis khususnya dalam membuat desain-desain Islam merupakan suatu kemampuan yang sangat diperlukan di era digital seperti saat ini, terutama bagi para pelajar dan mahasiswa. Hal tersebut berkaitan dengan mitra dalam Program Pengembangan Kemitraan Muhammadiyah adalah Pimpinan Cabang Ikatan Pelajar Muhammadiyah Medan Area yang seluruh anggotanya merupakan pelajar dan mahasiswa. Sementara itu, para Pengurus Pimpinan Cabang Ikatan Pelajar Muhammadiyah Medan Area masih belum memiliki kemampuan desain grafis terutama kemampuan dasar dalam membuat sebuah desain, sehingga dengan adanya kegiatan ini dapat membantu dan menambah wawasan atau pengetahuan serta kemampuan desain grafis yang dapat dijadikan sebagai kemampuan untuk membuat organisasi menjadi lebih berkembang. 
Pimpinan Cabang Ikatan Pelajar Muhammadiyah Medan Area juga merupakan salah satu Ortom Muhammadiyah yang memiliki gerakan Islam modern yang berwatak dengan sebuah tugas mulia untuk mewujudkan sebuah tatanan yang berlandaskan atas islam dalam rangka mewujudkan Masyarakat dan Pelajar Islam yang sebenar-benarnya dan menjadi pelopor, pelangsung dan penyempurna perjuangan terutama dalam Muhammadiyah. Oleh karena itu, Program Pengembangan Kemitraan Muhammadiyah yang dilaksanakan dapat meningkatkan kreativitas dakwah pada kaderkader PC IPM Medan Area agar dapat menyebarkan dakwah atau konten dengan menggunakan desain-desain Islami dan tidak menghilangkan nilai-nilai Kemuhammadiyahan itu sendiri.

\section{METODE}

Metode yang digunakan dalam menyelesaikan Program Pengembangan Kemitraan Muhammadiyah adalah dengan praktik langsung yang diikuti oleh 10 orang kader atau pengurus PC IPM Medan Area. Praktik kegiatan Program Pengembangan Kemitraan Muhammadiyah secara langsung tersebut dilaksanakan melalui empat tahapan, yaitu:

1. Pemaparan materi dan pengenalan aplikasi-aplikasi desain grafis dan fitur-fitur didalamnya.

2. Melakukan evaluasi dan diskusi terkait kegiatan sebelumnya.

3. Praktik pembuatan desain grafis yang Islami.

4. Pembinaan secara berkelanjutan agar pengurus PC IPM Medan Area dapat memiliki kemampuan desain grafis dalam membuat desain-desain yang islami.

\section{HASIL DAN PEMBAHASAN}

Pelaksanaan Program Kemitraan Pengembangan Muhammadiyah (PKPM) tentang Peningkatan Kemampuan Desain Grafis untuk Meningkatkan Kreativitas Dakwah pada PC IPM Medan Area telah dilaksanakan secara berkala diSekretariat PC IPM Medan Area. Pada Tahap 1, kader atau pengurus PC IPM Medan Area diberikan pemaparan materi terkait dengan dasar-dasar dari sebuah desain grafis, apa-apa saja yang perlu diperhatikan dalam membuat desain grafis, aplikasi-aplikasi yang dapat digunakan untuk membuat desain, lalu bagaimana teknik-teknik menentukan tema, isi, atau pesan yang akan disampaikan melalui desain tersebut, serta memberikan pengenalan aplikasi dalam pembuatan desain grafis beserta fiturfitur di dalamnya (Musmuliadi \& Purmadi, 2018; Sakti, 2017). Dokumentasi kegiatan disajikan pada Gambar 2.

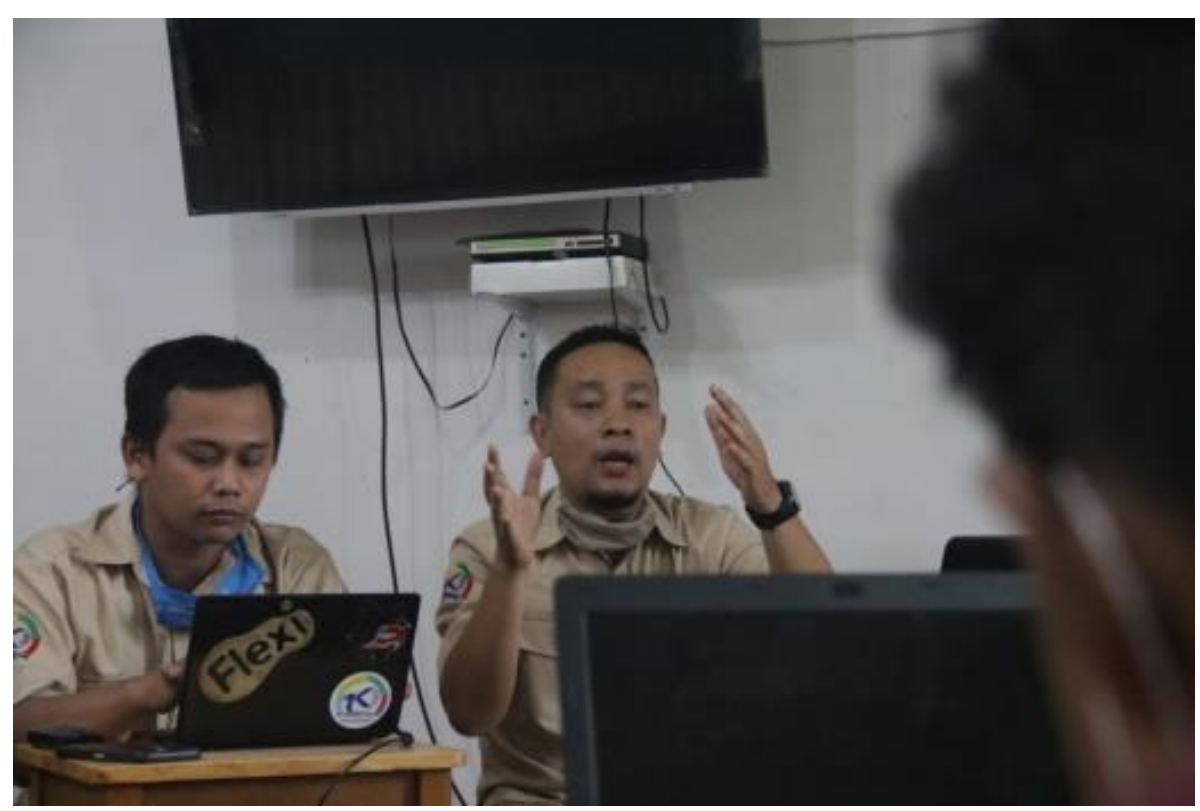

Gambar 2. Pemaparan materi desain grafis 
Pada tahap 2, para peserta kegiatan melakuan diskusi dengan pemateri terkait apa saja yang menjadi kendala atau masalah dalam penggunaan aplikasi dan memahami desain grafis. Dari sesi diskusi ini, para peserta mulai dapat memahami dan memiliki pengetahuan tentang bagaimana teknik membuat desain grafis yang baik dan bagus tanpa menghilangkan unsur-unsur islami. Kemudian Pada Tahap 3, melakukan praktik secara langsung dan para peserta diminta untuk membuat desain grafis yang islami tanpa menghilangkan nilai-nilai Kemuhammadiyahan. Berikut adalah beberapa hasil dari desain grafis yang dibuat oleh para peserta atau pengurus PC IPM Medan Area (Gambar 3):

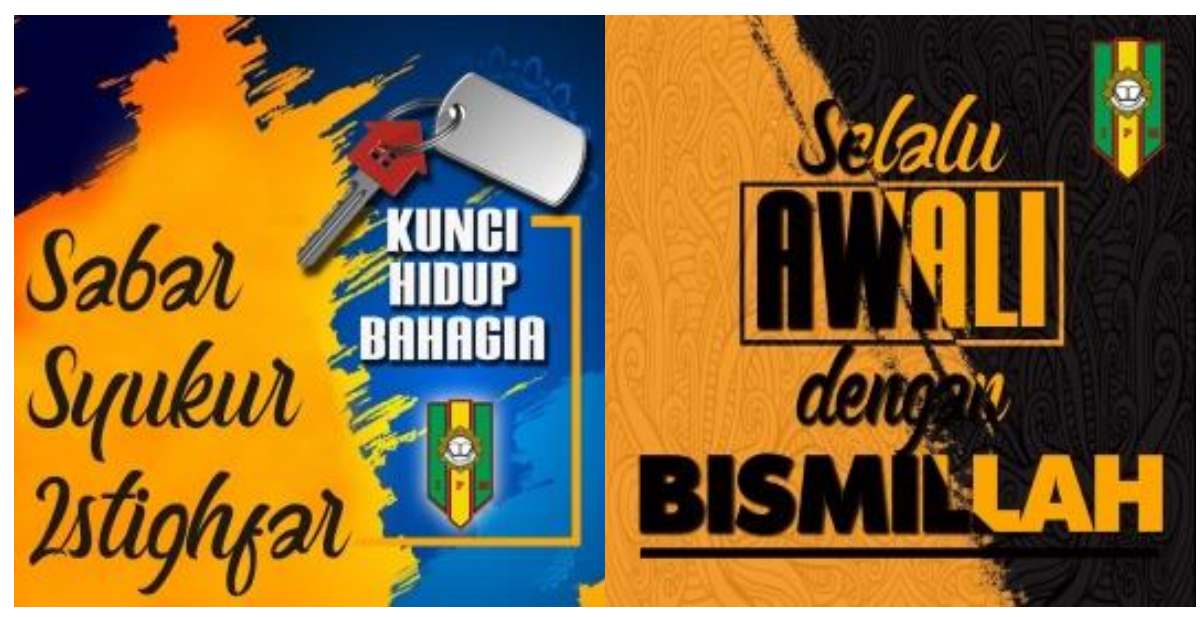

Gambar 3. Hasil Desain Grafis PC IPM Medan Area

Pada Tahap 4, setelah melakukan praktik, dan selanjutnya dilakukan pembinaan maka hasilnya para peserta PC IPM Medan Area telah mengalami peningkatan terutama dalam wawasan dan kemampuan dasar dalam desain grafis sebagai meningkatkan kreativitas dakwah para kader. Berbagai pengabdian telah dilakukan sebelumnya (Fahana et al., 2019) yang menyatakan bahwa, dengan memiliki keahlian atau kemampuan untuk desain grafis tidak hanya dapat meningkatkan kemampuan kreativitas atau seni saja bagi seseorang akan tetapi juga dapat menjadi salah satu untuk cara untuk meningkatkan kreativitas seseorang dalam mendesain pesan/isi yang digunakan sebagai berdakwah yang dapat menyiarkan ajaran Islam dan nilai-nilai Kemuhammadiyahan dalam era digital saat ini.

\section{KESIMPULAN}

Setelah Pelaksanaan yang dilakukan oleh tim Program Kemitraan Pengembangan Muhammadiyah (PKPM) UMSU yang berjudul "Peningkatan Kemampuan Desain Grafis untuk Meningkatkan Kreativitas Dakwah pada PC IPM Medan Area” maka dapat diambil kesimpulan, bahwa melalui kegiatan ini PC IPM Medan Area mendapatkan pengetahuan, pemahaman, serta kemampuan dalam menciptakan desain-desain grafis. Namun kader-kader PC IPMMedan Area masih dalam tahap proses belajar sehingga belum secara keseluruhan dapat membuat hasil desain grafisnya. Program Kemitraan Pengembangan Muhammadiyah (PKPM) membuat beberapa para peserta dapat mengimplementasikan hasil kreativitas peserta dan menghasilkan desain grafis dakwah yang menarik di era digital ini.

\section{UCAPAN TERIMA KASIH}

Terima kasih kepada Universitas Muhammadiyah Sumatera Utara, khususnya Lembaga Penelitian dan Pengabdian Masyarakat Universitas Muhammadiyah Sumatera Utara (LPPM UMSU) atas bantuan dana Program Kemitraan Masyarakat dengan Skim Program Kemitraan Pengembangan Muhammadiyah (PKPM) tahun 2021 sehingga PKPM ini dapat dilaksanakan. 


\section{REFERENSI}

Fahana, J., Ma'ruf, F., Umar, R. 2019. Pendampingan dan pelatihan Google APP dan design grafis pada eksekutif Muhammadiyah D.I. Yogyakarta. Prosiding Seminar Nasional Hasil Pengabdian Kepada Masyarakat Universitas Ahmad Dahlan. 1:351-356

Kusrianto, A. 2009. Pengantar Desain Komunikasi Visual. Yogyakarta: Penerbit Andi

Lisnawita, Van, L.L., Musfawati. 2020. Pelatihan Desain Grafis Untuk Meningkatkan Kreatifitas Siswa. Dinamisia: Jurnal Pengabdian Kepada Masyarakat. 4(2):231-235. https://doi.org/10.31849/dinamisia.v4i2.3406

Murdiati, Ferawaty, Hita. 2020. Pelatihan Desain Grafis untuk Meningkatkan Kreativitas Siswa pada SMA Husni Thamrin. Jurnal Pendidikan dan Pengabdian Masyarakat.3(2):96-100

Musmuliadi, Purmadi, A. 2018. Pengaruh Media Desain Grafis Berbasis Adobe Photoshop terhadap Kreativitas Belajar Siswa. Jurnal Teknologi Pendidikan : Jurnal Penelitian dan Pengembangan Pembelajaran. 3(1):20-28. https://doi.org/10.33394/jtp.v3i1.1223

Pratiwi, D.A., Danugiri, D. 2020. Pelatihan Desain Grafis Dalam Meningkatkan Kompetensi Kewirausahaan di BLK Kabupaten Karawang. Journal of Community Education (JoCE).1(1):43-48. https:// doi.org/10.35706/joce.v1i1.3879

Sakti,H.G. 2017. Pengaruh Media Desain Grafis Berbasis Adobe Photoshop terhadap Kreativitas Belajar Siswa Kelas X pada Mata Pelajaran Desain Grafis. Realita : Jurnal Bimbingan dan Konseling. 2(2):325-344. https://doi.org/10.33394/realita.v2i2.756

Walisyah, T. 2019. Bentuk-Bentuk Komunikasi Visual Dalam Periklanan. Jurnal Komunika Islamika: Jurnal Ilmu Komunikasi dan Kajian Islam. 6(1):33-57. https://doi.org/10.37064/jki.v6i1.5518

Widya, L.A.D., Darmawan, A.J. 2016. Bahan Ajar Kursus dan Pelatihan Desain Grafis. Jakarta: Direktorat Pembinaan Kursus Dan Pelatihan Direktorat Jenderal Pendidikan Anak Usia Dini Dan Pendidikan Masyarakat Kementerian Pendidikan Dan Kebudayaan Republik Indonesia

Yahya, F., Hermansyah, Syafruddin, Fitriyanto, S., Musahrain. 2020. Pelatihan Desain Grafis Untuk Kelompok Pemuda Kreatif Desa Gontar Kecamatan Alas Barat Kabupaten Sumbawa. Jurnal Pendidikan dan Pengabdian Masyarakat. 3(2):114-118 